\title{
Categorías en La oración y sus partes (1920) de Rodolfo Lenz: Clases
}

\author{
José J. Gómez Asencio* \\ Universidad de Salamanca, España
}

\begin{abstract}
Resumen
En este trabajo se pretende sacar a la luz, desentrañar e interpretar en perspectiva historiográfica algunas de las ideas de Rodolfo Lenz (1920) relativas a la categorización verbal. Como punto de partida para la cabal comprensión de las categorías verbales en este autor, se examina su posicionamiento en lo relativo a la oración como unidad lingüística fundamental y en tanto que marco en el que tienen lugar las relaciones entre los elementos. El trabajo se centra posteriormente en las categorías verbales (partes de la oración o clases de palabras) y analiza en perspectiva interpretativa y crítica los tres sistemas alternativos y complementarios de categorías verbales que Lenz defiende mediante la aplicación de criterios definitorios alternativos: formal, semántico-lógico y funcional, de los cuales el último es para Lenz prioritario. Finalmente, se exhibe un resumen conclusivo de los tres sistemas de Lenz confrontados entre sí y con el sistema de diez clases de palabras de la gramática tradicional, y se trata de valorar la importante aportación de Lenz.

Palabras clave: historia de la gramática española, oración, categorías verbales, partes de la oración, Rodolfo Lenz.
\end{abstract}

Para correspondencia, dirigirse a: José J. Gómez Asencio (gasencio@usal.es), Departamento de Lengua Española, Universidad de Salamanca, Plaza de Anaya s/n, 37008 Salamanca, España. 
Categories in Rudolf LenZ's LA ORACiÓN Y SUS PARTES (1920):

CLASSES

\begin{abstract}
This paper intends to bring to light, unravel and interpret some of the ideas of Rudolf Lenz (1920) concerning verbal categorization in historiographical perspective. As a starting point, we examine Lenz's position with regard to the sentence as a fundamental linguistic unit and as a framework in which the relationships between its components take place. The work subsequently focuses on verbal categories (parts of speech or word classes) and analyzes in an interpretative and critical perspective the three alternative and complementary systems of verbal categories proposed by Lenz applying alternative defining criteria: formal, logico-semantical and functional, the latter being prioritary for Lenz. Finally, it presents a summary of the three systems of Lenz confronted with each other and with the system of ten parts of speech in traditional grammar, and it assesses Lenz's significant contribution.
\end{abstract}

Keywords: history of Spanish Grammar, sentence, verbal categories, parts of speech, Rudolf Lenz.

Recibido: $15 / 03 / 16 \quad$ Aceptado: 06/05/16

\title{
1. LA ORACIÓN Y SUS PARTES: EDICIONES E INTERVENCIONES (DE 1920 A 1944) ${ }^{1}$
}

Las ediciones del texto de las que se tiene noticia (la 4a de 1944 se publicó después de la muerte de Lenz) quedan referidas por su último editor:

1 Este trabajo ha sido posible gracias a una Estancia de movilidad de investigadores en centros extranjeros desarrollada en la Universidad de Chile subvencionada por el Ministerio de Educación, Cultura y Deporte de España (PR2015-00019). Por lo demás, se inserta dentro del proyecto de investigación Pretérito perfecto simple y pretérito perfecto compuesto: Historiografía, gramatización y estado actual de la oposición en el español europeo (FFI201345914-P), financiado por el Ministerio de Economía y Competitividad español. 
93. La oración y sus partes, Madrid, Centro de Estudios Históricos, 1920.

Segunda edición, ibidem, 1925. Tercera edición, Madrid, 1935 [Impresión en Avila]. Cuarta edición, con algunas modificaciones, en Santiago, Nascimento, 1944, al cuidaclo del autor de estas líneas.

(Escudero 1963:479)

Todo apunta a que no hay (al menos grandes) cambios entre $1^{\mathrm{a}}-1920$ y $2^{\mathrm{a}}$ 1925; de hecho, en esta se lee:

\section{PREFACIO A LA SEGUNDA EDICIÓN}

Todavía no se han introducido cambios mayores en el libro. Estoy esperando más reseñas críticas para ver en qué sentido conviene alterar la composición. Las citas de la Gramática de la Real Academia se refieren a la edición del año rgr3. Sólo algunas veces he citado expresamente Gramática Reformada refiriéndome a la edición de 1917 , que trae tan importantes mejoras. Compárese para el efecto mi publicación: La Enseñansa del Castellano y la Reforma de la Gramática. Santiago de Chile, I920. ¡Ojalá que la Real Academia siga pronto en el camino del progreso!

Dr. Rodolfo Lenz.

Aunque algunos sí que se encuentran:

(i) en $1^{\mathrm{a}}$-1920 no aparece y en $2^{\mathrm{a}}$-1925 sí el subtítulo: Estudios de gramática general y castellana.

(ii) en la portada de $2^{\mathrm{a}}$-1925 la palabra oracion aparece así, sin tilde (en $1^{\mathrm{a}}$-1920 la llevaba. En $3^{\mathrm{a}}-1935$ se repone y en $4^{\mathrm{a}}$-1944 se vuelve a perder: jestos impresores!).

(iii) al final del Sumario se añade una observación sobre la pronunciación de ciertos sonidos mapuches, entre ellos la [y] velar: 


\begin{tabular}{|c|c|}
\hline \multicolumn{2}{|l|}{1920} \\
\hline & 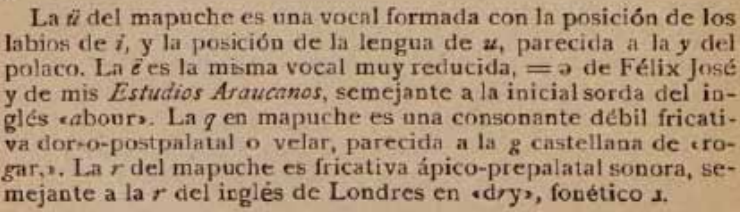 \\
\hline \multicolumn{2}{|c|}{1925 y siguientes } \\
\hline & $\begin{array}{l}\text { La ï del mapuche es una vocal formada con la posición de los } \\
\text { labios de } i \text {, y la posición de la lengua de } u \text {, parecida a la } y \text { del } \\
\text { polaco, La } \ddot{e} \text { es la misma vocal muy reducida, = } e \text { de Félix } \\
\text { José; } \text { y de mis Estudios. Aroucanos, semejante a la inicial sor- } \\
\text { da del inglés "about". La } q \text { en mapuche es una consonante } \\
\text { débil fricativa dorso-postpalatal o velar, parecida a la } g \text { cas- } \\
\text { tellana de "rogar". La } r \text { del mapuche es fricativa ápico-pre- } \\
\text { palatal sonora, semejante a la } r \text { del inglés de Londres en "dry", } \\
\text { fonética } r \text {. La } n \text { del mapuche es velar, equivale a la } n \text { castella- } \\
\text { na delante } c \text { o } g \text { (banca, tengo), la ng del inglés singing; } t ; l \text {. } \\
n \text {. significan consonantes ápico-dentales. }\end{array}$ \\
\hline
\end{tabular}

(iv) a partir de 2a-1925 los párrafos numerados (del 1 al 358) llevan, en negritas, un título que da idea de su contenido. Esto no se encuentra en $1^{\mathrm{a}}-1820$.

(v) las Adiciones y correcciones de 1a-1920 (pp. 543-545) desaparecen a partir de $2^{\mathrm{a}}$-1925, para pasar a integrarse en su lugar correspondiente (en texto o en notas).

Por su parte, en la $3^{\mathrm{a}}$-1835, impresa en Ávila, se repite exactamente el Prólogo a la segunda edición, que se acaba de reproducir. Y nada sugiere modificaciones, ni de forma ni de contenidos con respecto a la versión previa $^{2}$.

2 La $3^{\text {a }}$-1935 es, pues, la última que pudo ser revisada por el propio autor (fallecido en 1938), pero a juzgar por lo que dice Escudero en la Advertencia que se cita en el texto, no lo fue; es más, Lenz ni siquiera llegó a saber nada de ella, dadas las circunstancias:

Entre tanto, habia aparecido (Ventro de Estudios mustorcos, Madrid, 1935, pero impresa en Avila) una tereera edición en la que para nada intervino el autor $y$ de la cual (como consectencia de la guerra cspafiola) tampoco supo nada.

No debería, por consiguiente, ser el texto base de este trabajo. 
La 4a-1944 es la única publicada en Chile, en Santiago concretamente, por la Editorial Nascimento; se encargó de la edición el agustino Alfonso M. Escudero, quien incorpora una Advertencia a la cuarta edición, especialmente interesante ${ }^{3}$ porque en ella se nos da a conocer cómo Lenz disponía de un ejemplar de la 2a -1925 , "que él llamaba su Handexemplar", donde "iba anotando las modificaciones -leves- que proyectaba para la tercera edición. Pero sobrevino la muerte (7-IX-1938)". A esta cuarta edición trasladó Escudero las "enmiendas indicadas o insinuadas" por Lenz en su particular ejemplar. Se insinúa, pues, esta como la edición preferible para nuestros propósitos y será la efectivamente tenida en cuenta a partir de ahora.

Lenz asumió un papel difícil, una responsabilidad arriesgada: escribir en Chile una gramática del español después de Bello y hacerlo sin seguirlo ciegamente (para compendiarlo, copiarlo, reproducirlo, adaptarlo, elogiarlo, como otros muchos habían hecho antes que él $\left.{ }^{4}\right)$. No debía de ser tarea fácil tras el excelente trabajo de Bello o tras la merecida e inmensa fama del polígrafo venezolano-chileno. Lenz apostó, sin embargo, por ello y se puso manos a la obra.

Lenz consideró que el texto de Bello era la mejor de las gramáticas del español existentes ${ }^{5}$, y se inspiró generosamente en este tratado. No todos los juicios de Lenz acerca de Bello son precisamente encomiásticos, sin embargo, y hay muchos que distan de serlo, tantos que no podrán ser objeto de nuestra atención ahora (nos ocuparemos de esta cuestión en un trabajo posterior).

\footnotetext{
Además, se añade una Bibliografía antes del índice alfabético de materias; el Sumario que se encontraba al principio hasta 1944 pasa al final del libro, tras el índice de materias; y alguna otra modificación menor en absoluto doctrinal ni descriptiva.

4 Por cierto que ese es un capítulo de la gramaticografía del español que se encuentra a la espera del detallado estudio que se merece.

5 "Uso como libro fundamental la Gramática castellana de Andrés Bello en la edición anotada por R. J. Cuervo. Esta obra es, sin duda, el compendio más completo y más concienzudo que existe respecto a la gramática moderna de la lengua española" (\$5).
} 


\section{CLASES - RASGOS - RELACIONES}

\subsection{LA EQUIVOCIDAD DE “CATEGORÍA” EN GRAMÁTICA}

Aunque a menudo se utiliza CATEGORÍA para referirse exclusivamente a las clases de palabras (mere tou logou; partes orationis), entendemos que -en un estudio de historiografía gramatical como el presente (Swiggers 2009 y Gómez Asencio 2015b)- bajo ese término deberían integrarse, y ello además en consonancia con el propio modelo teórico-conceptual en el que se inserta Lenz, estas tres realidades:

(i) unidades del sistema, CLASES (partes y subpartes de la oración, clases y subclases de palabras, categorías y subcategorías verbales), constituidas por conjuntos paradigmáticos de elementos concretos, por entidades de carácter léxico. Serían las frecuentemente llamadas categorías verbales: clasificación de las entradas o elementos léxicos de una lengua en tipos en función de ciertos caracteres compartidos $\mathrm{y}$ atendiendo a diversos criterios: nombre, adverbio, pronombre, posesivo, adversativa, numeral, etc.

(ii) tipos de RASGOS, esto es, propiedades (los “accidentes" de la gramática escolar) de naturaleza gramatical sin existencia autónoma exenta, características que se superponen / añaden / adosan / afectan a las clases. Caben aquí las a menudo denominadas categorías gramaticales: caso, imperativo, impersonal, futuro, activa, masculino, etc.

(iii) modelos de RELACIONES, funciones entre clases o entre rasgos, o procedimientos lingüísticos, heurísticos o probatorios: regir, transitividad, sujeto, atributo, predicado, complemento, subordinación, término, antecedente, orden, ¿¿¿oración???, etc.

No parece que sea necesario justificar aquí la imposibilidad de analizar con exhaustividad y algo de rigor todas esas CATEGORÍAS en un texto tan rico, denso, complejo y novedoso como el que me ocupa en esta ocasión. Volveremos sobre el asunto en otra ocasión futura con la aspiración de completar esa tarea. Por ahora, más modestamente, atenderé lo mejor que sepa y pueda a las arriba llamadas CLASES, las categorías verbales comúnmente denominadas clases de palabras, partes de la oración, parties du discours, parts of speech, etc. 


\subsection{CRITERIOS Y PERSPECTIVAS PARA UN ANÁLISIS INTERPRETATIVO DE NATURALEZA HISTORIOGRÁFICA}

La herramienta de análisis de las categorías verbales tipificadas en los textos gramaticales del pasado -historiografía de la gramaticografía-que expondré sucintamente a continuación (Gómez Asencio 1981) se ha revelado eficaz para sus propósitos en numerosos estudios previos (propios y ajenos). En esta ocasión se aplicará también al texto de Lenz, no tanto por comprobar la validez de la herramienta cuanto por tratar de desentrañar aspectos del sistema de clases de palabras del autor chileno-alemán con la voluntad de interpretarlo y entenderlo justamente, en sí mismo y por su cotejo con la tradición gramatical de la que él mismo forma parte.

\begin{tabular}{|l|l|l|}
\hline \multirow{2}{*}{ PERSPECTIVA } & \multicolumn{2}{|c|}{ CRITERIO } \\
\hline \multirow{4}{*}{ intraoracional - intradiscursiva } & \multicolumn{2}{|c|}{ formal y morfosintáctico } \\
\cline { 2 - 3 } & \multirow{2}{*}{ sintático } & puro \\
\cline { 2 - 3 } & semántico & teleológico \\
\cline { 2 - 3 } & & colocacional-combinatorio \\
\cline { 3 - 3 } & & en sentido amplio \\
\hline \multicolumn{2}{|c|}{ Tabla I. Criterion y perspectivas de análisis } \\
\hline
\end{tabular}

\subsection{Palabras, Clases de palabras y partes de la oración}

2.3.1. Aunque en numerosas ocasiones a lo largo de la tradición gramatical hispánica los términos que figuran en el título de este apartado se han considerado sinónimos o se han manejado indistintamente, no debería ser así en un análisis historiográfico que aspire a interpretar y comprender esa tradición. Así, mientras que "clases de palabras" debería sugerir una perspectiva paradigmática, extradiscursiva por tanto, las "partes de la oración" deberían ser el resultado de un análisis intraoracional o, a lo menos, intradiscursivo, donde la unidad ORACIÓN se constituyera como punto inicial de arranque de la teoría.

Todo apunta a que para el primer gramático de occidente (citado, por cierto, por Lenz 1944: 23), Dionisio de Tracia, palabra (lexis) y parte de la oración (meros logou) son equivalentes; no en vano comienza la definición teórica de cada una de las ocho que categoriza indistintamente de una u 
otra manera: "nombre: parte de la oración que...", "preposición: palabra que...”, etc.

La PALABRA = PARTE DE LA ORACIÓN se configura aquí -y en la tradición instalada sobre este texto pionero- como la unidad base a partir de la cual por síntesis (combinación: sýntaxin) se consiguen oraciones y por análisis (descomposición), sonidos o sílabas o trozos de palabras; se encuentra, así, en el centro de toda la actividad lingüística y en el núcleo del análisis metalingüístico y gramatical. $\mathrm{Y}$, de hecho, nada sugiere (sino todo lo contrario) que la unidad oracional constituyese un punto de partida para el análisis gramatical del lenguaje:

La palabra [lexis-dictio] es la parte más pequeña de la oración. La oración [logos-oratio] es la combinación ordinaria de palabras que muestra un sentido completo. Las partes de la oración [meros logou-partes orationis] son ocho [...] (Dionisio Tracio §11) (traducción de Bécares).

Si se atiende a la cita que se acaba de transcribir, se descubrirá que las definiciones de las dos grandes unidades de la gramática pecan de tautología, son circulares y en el fondo el lector se queda sin saber en qué consiste cada una; más o menos:

Palabra $\rightarrow$ parte / trozo de la oración, pedazo de discurso

Oración $\rightarrow$ combinado de palabras o fragmentos (ordinario, normal, y con sentido "completo")

Se construyen, así, sobre un sistema de remisiones o reenvíos de la una a la otra, y de la otra a la una, y no se alcanza a proponer una definición intrínseca o inherente de ninguna de ellas.

2.3.2. Por lo demás, deberíamos considerar cómo, por su lado, PARTE DE LA ORACIÓN es término equívoco. Para tratar de arrojar algo de luz en esta cuestión, nos serviremos de un paralelismo ajeno por completo a la gramática: partes de una casa refiere (casi) por igual (a) que (b):

(a) ladrillos, paredes, fregadero, lavadora, radiador, cemento, lavabo, cables eléctricos, ventanas, puertas, tuberías, sofá, etc.

(b) cocina - baño - salón - dormitorio principal - cuarto de invitados pasillo

En (a) figuran elementos variados que se encuentran en una casa, componentes constitutivos -necesarios o contingentes; estructurales o añadidos- de ella. En (b) se plasman piezas relevantes y funcionales en que se puede dividir la 
casa según un determinado criterio (en este caso, el destino de las diversas estancias o módulos de que se compone/que la integran).

Situados en perspectiva extradiscursiva, ajena al sintagma, términos como nombre, participio, preposición, interjección, verbo, artículo etc. harían referencia a componentes paradigmáticos que podrían encontrarse en una oración, elementos con los que, eventualmente, podrían construirse oraciones: sentido (a) de arriba. Lo mismo definiciones de esta naturaleza:

Nombre: palabra con caso y género, sin tiempo ni voz

Verbo: palabra con tiempo y voz sin caso ni género

Participio: palabra con caso, con género, con tiempo y con voz

Ubicados en una perspectiva intraoracional, sintágmática y funcional, esos mismos términos podrían recubrir el sentido (b) de arriba:

Verbo: palabra que constituye el núcleo del predicado

Sustantivo: palabra que constituye el núcleo del sujeto

2.3.3. Buena parte de la tradición gramatical hispánica se asienta sobre supuestos como los que se acaban de presentar en los apartados previos: palabra en el centro (hasta el punto de que constituyen legión los textos que ni siquiera ofrecen una "Sintaxis", esto es, que no se ocupan de la combinatoria de las unidades en otras mayores, y solo se tratan aspectos de la naturaleza interna de las clases léxicas); circularidad de las definiciones; consideración de las PARTES DE LA ORACIÓN en el sentido (a) de arriba, como componentes categoriales constitutivos "ajenos" al todo oración.

Lenz, deliberadamente, se sitúa al margen de esa tradición, fuera de ella, y en esto consiste uno de sus aportes teóricos innegables:

(i) define de modo autónomo e inherente ORACIÓN, y por referencia o remisión a este término-concepto define PARTE DE LA ORACIÓN; de ahí el título de la obra: La oración y sus partes, un texto que, en buena medida, lo que contiene es algo comúnmente tratado en libros llamados Gramática española o castellana.

(ii) como ese propio título sugiere, la unidad lingüístico-gramatical de la que se parte, aquella que sirve de armazón en el que se sustenta todo lo demás es justamente la ORACIÓN, y no la PALABRA ni la PARTE DE LA ORACIÓN.

(iii) distingue PALABRA en tanto que clase (expresión de concepto) de PARTE DE LA ORACIÓN en tanto que relación o función. Son y no son la misma cosa: aquella trabaja como elemento categorial "autónomo" dotado 


\section{de cierto significado léxico; esta como componente o pieza relacional dentro de una entidad superior. En todo caso:}

La palabra misma es una subdivisión de la oración, cuyas partes constituyentes están en una relación más o menos estable, de modo que la misma configuración fonética puede entrar como elemento constituyente en muchas oraciones $(\$ 17)^{6}$.

[es muy difícil definir palabra] Con seguridad solo puede decirse que es una parte de la oración en el sentido propio, es decir, una subdivisión de la oración (\$36).

Podría quizá aceptarse para el uso escolar en lengua castellana una definición como la siguiente: La palabra es una subdivisión de la oración que se compone de un grupo de sonidos completamente invariable, o variable en la terminación, y que corresponde a cierta unidad de sentido $(\S 45)^{7}$.

6 El párrafo es difícil. Creo que lo que se quiere decir es esto: (i) la palabra es un trozo de enunciado; (ii) los fragmentos que, juntos, constituyen el enunciado guardan entre sí una relación invariable (por ejemplo: SN con respecto de SV y viceversa; sustantivo SN con adjetivo SAdj; etc.); (iii) como esa relación abstracta es estable, su hueco puede ser ocupado por cualquier entrada léxica, es decir, por cualquier palabra concreta (entiendo que esto lo que se quiere decir con "configuración fonética").

7 Lenz suele estar atento a lo que representaría llevar sus afirmaciones hasta las últimas consecuencias, esto es, a las contradicciones o incongruencias a las que pueden conducir, y es capaz de predecir soluciones a tales inferencias extremas (en realidad: excepciones que anulan la aplicación general/verdad universal de la propuesta). Concretamente, en este caso añade: "Se prescinde en esta definición del hecho excepcional de que una palabra pueda ser formada de una sola vocal [contra grupo de sonidos] y de casos como hago-hice [contra variable en la terminación]".

Y más adelante (\$220): "Hago e hice, que expresan el mismo concepto (hacer) y la misma relación con primera persona singular de indicativo, de modo que sólo varía el tiempo de presente a pretérito, conserva [sic] sólo la $h$ muda, es decir, en el verdadero lenguaje, nada, para indicar el concepto en sí" (el subrayado, mío, trata de reflejar que, en verdad, las palabras -al menos algunas- significan conceptos). 


\section{LA ORACIÓN...}

\subsection{LA LECCIÓN HISTORIOGRÁFICA: DOS ABORDAJES DIFERENTES}

Como ya se ha sugerido más arriba, en historiografía de la gramática se dibujan a este respecto dos grandes tendencias igualmente legítimas (o ilegítimas) (Gómez Asencio 2014a, 2014b y 2015a):

(i) la de aquellos gramáticos que parten de la palabra como unidad matriz, como entidad monoverbal formal que sirve de base para todo el constructo gramatical. La oración, dado el caso, sería una entidad subsidiaria/segunda/posterior que resultaría de cierto conglomerado o acopio de palabras tolerado o exigido por la lengua.

Esas palabras serían elementos que, sumándose uno tras otro según ciertas condiciones, constituirían una unidad superior, la oración.

(ii) la de aquellos otros que parten de unidades mínimas de comunicación y de información "autónoma" [de ahí lo del sentido completo] exentas (aisladas por pausas-comas) cuya forma material real solo es considerada a posteriori. Una vez definidas, configuradas y aisladas desde esa doble perspectiva de: (a) su autonomía sintácticofonológica; y (b) su aporte comunicativo (pragmático y semántico), se examina su interior, su estructura y se las descompone en entidades más pequeñas; esto es, son sometidas a un proceso de análisis.

\subsection{LA POSICIÓN DE LENZ}

Lenz se ubica en este segundo grupo, el de quienes consideran que la ORACIÓN es el marco en el que suceden las cosas, en el que tienen lugar las relaciones, las que sean:

La unidad natural del lenguaje no es la palabra, como antes se creía, sino la oración, o, digámoslo mejor, la frase, la comunicación ${ }^{8}$, para prescindir de todo carácter gramatical determinado (§17).

8 Salvo que se especifique lo contrario, todos los subrayados del texto son míos. 
El título del libro, por lo demás, deja bien claro esto.

3.2.1. En términos y consideraciones actuales, el abordaje que Lenz hace de esta unidad lingüística no es -a mi ¿moderno y anacrónico? entender ${ }^{9}-$ ni estrictamente gramatical, quiero decir de gramática técnica, de gramática "estructural", formal (unión de SN y SV, concordancia, presencia de un verbo en forma personal, etc.); ni estrictamente semántico (sentido completo; unidad mínima de predicación).

Lo primero, lo de la pura forma, debe de tener que ver con que Lenz no trata solo de la (estructura de la) oración en la lengua española, sino de "gramática general" 10 , y es sabido que las cuestiones de naturaleza estructural-formal suelen ser propias de cada lengua o de grupos de varias de ellas, y difícilmente se presentan como universales, es decir, raramente son válidas para todas las lenguas. Tal vez desde esa clave interpretativa se podría justificar el desapego mostrado por Lenz hacia una definición intra-lingüística gramatical-formal, y su atracción por una definición interlingüística "psicológica".

Lo segundo, lo del sentido completo como rasgo definidor de esta unidad lingüístico-gramatical -algo válido en principio y en apariencia para todas las lenguas-, es objeto de contraargumentación explícita por parte de Lenz (con la ayuda de Wundt):

$1^{\circ}$. "la enumeración de los días de la semana tiene sentido completo; pero no es una oración" (\$14).

$2^{\circ}$. “'Él nos conoce”, es gramaticalmente una oración completa e independiente, pero no tiene sentido completo, porque él y los no expresan conceptos sino que repiten conceptos antes dichos, que debo conocer para que la oración tenga sentido completo" ( $\$ 339$ nota).

3.2.2. En perspectiva retrospectiva, Lenz se apoya $-y$ así lo reconoce por doquier a lo largo del texto- y sustenta su propuesta en los puntos de vista

9 Pero sí al suyo: "Las definiciones de la oración han vacilado desde antiguo entre dos extremos: el gramatical y el lógico. Gramatical es la definición de Dionisio de Tracia: "La oración (logos) es una unión de palabras que representan un sentido completo". Así dice todavía Bello, Gramática, §308: "Se llama oración toda proposición o conjunto de proposiciones que forman sentido completo"” $(§ 13)$. Por mi parte, considero que tales definiciones están más próximas al criterio semántico que al gramatical.

10 Véase el subtítulo del libro a partir de su segunda edición: Estudios de gramática general y castellana. 
e ideas de psicología lingüística sostenidos por Wundt ${ }^{11}$. En perspectiva prospectiva, ambos -maestro y discípulo- apuntan maneras que más tarde serían: (a) o bien formuladas como "análisis lingüístico de los hechos compactos de experiencia: primera articulación del lenguaje", (b) o bien presentadas desde la pragmática comunicativa y el análisis del discurso como utterance, statement, enunciados a la postre.

(i) unidades mínimas de percepción, de formulación y de información de cada experiencia propia de cada cual.

(ii) unidades mínimas de comunicación dotadas, en perspectiva semántico-pragmática, de un sentido completo y concreto; esto quiere decir: referido (a) a un universo del discurso compartido por los participantes en el acto de habla, (b) a la situación comunicativa, y (c) al contexto en el que se enuncia.

3.2.3. Lenz parte de la premisa -extralingüística- de que la formación de conceptos y juicios por parte del ser humano arranca/surge normalmente a partir de una representación total -global, compacta, sintética, integral, "apelmazada" - de aquella parte de la realidad o de la experiencia personal sobre la que se desea llamar la atención o de la que se quiere informar (§16): cada cual en primer lugar "se hace una idea" [el término es mío] de aquello de lo que querría hablar. Para transmitir por medio del lenguaje esa representación mental global, ideal y abstracta, es necesario des-integrarla en sus componentes, des-globalizarla, des-componerla en fragmentos sucesivos:

El procedimiento es, en primer lugar, analítico, porque descompongo la unidad de la representación total en sus elementos; pero a la vez hago una síntesis, porque cada elemento entra en relación lógica con el próximo. La oración entera está presente en mi conciencia simultáneamente, y sin embargo, las palabras entran en el centro visual sucesivamente $(\S 16)^{12}$.

11 "Si hacemos el análisis [...] de una representación total en dos elementos sucesivos, llegamos a la formación de un juicio. El juicio [...] es la descomposición de la representación total en sus representaciones parciales" (§12).

12 Linealidad del lenguaje, pues. Y sigue:

Si no fuers asi, ¿como podriamos hacer concordancta entre । adjetivo $y$ el substantivo que todavia no se ha pronunciad o entre un verbo puesto al comienzo, seguido quizá de vari complementos de diferentes especies, y finalmente por los su; tos? Cuando un orador poco diestro no alcanza a tener preser toda la construcción comenzada, entonces decimos que ha pi 
La oración o proposición ${ }^{13}$ (al menos desde el punto de vista de la gramática general) queda definida de este modo:

La oración es la expresión fonética (o lingüística) de la descomposición intencional de una representación total en sus elementos lógicamente relacionados $(\S 19)$.

Se suscitan estas reflexiones:

(i) el criterio que mejor se ajusta a la definición es el semántico (o, como el propio Lenz quiere, psicológico); del formal-gramatical o sintáctico se hace caso omiso;

(ii) la oración es una unidad de naturaleza lingüística (generalmente transmitida por canal oral; de ahí lo de "fonética"), no mental;

(iii) es el producto de un análisis lingüístico del pensamiento o de la experiencia;

(iv) sus elementos componentes guardan estrechas relaciones entre sí;

(v) es una unidad de sentido, un concepto próximo -si no idéntico- al que modernamente referimos como enunciado.

3.2.4. En el marco de la oración tienen lugar relaciones entre los elementos que la componen; la más evidente de estas relaciones es el orden de dichos elementos. El primer corolario que deriva de aquí es que toda oración normal debe estar compuesta por más de una palabra: al menos por la "expresión de dos conceptos", lo que en principio parece que deba ser entendido como 'por dos palabras sucesivas como mínimo'.

como entre unas y otras oraciones. Pues está en la misma re ćón el discurso entero para con cada una de las oraciones que forman, que cada una de las oraciones para con las palabras que se componen, $y$ hasta, en ciertas circunstancias, los elemen' en que se descompone la palabra están en paralelismo con palabras en que se descompone la oración.

13 Todo apunta a que proposición y oración en esta obra, por un lado, son términos sinónimos que se usan indistintamente y que recubren el mismo concepto; tal es lo que se encuentra a menudo, y clarísimamente aquí: "muchas gramáticas prescinden completamente de una clara definición de la proposición $\boldsymbol{u}$ oración" (\$13). Por otro lado, proposición se refiere también a la dominante (o principal) y a la subordinada de una oración compuesta. Además (\$351), se sostiene que en "terminología científica" se podría reservar oración para referirse al contenido (definición transcrita en el texto) y proposición para referirse "al aspecto gramatical e indicar la unión lingüística entre el sujeto y su predicado". 
3.2.5. Las formulaciones de Lenz acerca de la ORACIÓN dejan, sin embargo, algunos problemas/cuestiones pendientes, algunas puertas abiertas. El autor sale al paso de algunas de ellas (vid. supra nota 7); no así de otras.

Primera. El caso de la oración normal. ¿Qué hacer con las que no contienen "al menos la expresión de dos conceptos"?: ¿no son normales o no son oraciones? Parece que sí son oraciones y que Lenz en realidad define el prototipo: son prototípicas aquellas que cumplen con todos los requerimientos que se exigen desde la teoría que define, delimita y precisa este concepto-término; no lo son aquellas que incumplen algún requisito. La realidad lingüística concreta es terca y no siempre se ajusta a la teoría general que trata de preverla y dar cuenta de ella de modo integrado; parece razonable y positivo que esa teoría - abstracta y general- tenga prevista esta incidencia -concreta y particular- que ciertas lenguas en ciertas circunstancias predecibles pueden presentar.

Ahora bien: no se muestra Lenz muy tolerante con aprobar actitudes semejantes en otros gramáticos: (a) sostiene que la definición de sustantivo de Bello "flaquea [...] por un "puede" que le parece inevitable al autor: "El substantivo es una palabra que puede servir para designar el sujeto de la proposición"” (§7): a mi entender, la definición de Bello es clara y acertada; (b) de la GRAE dice: "La definición del verbo es muy poco satisfactoria: "Verbo es una parte de la oración que designa estado, acción o pasión, casi siempre con expresión de tiempo y de persona". Este casi permite que estado, acción, pasión, etc. se consideren como verbos" (\$8): parece claro que el casi era una salvaguarda que permitía que infinitivo o gerundio fuesen formas del verbo. Etc. La cooperación del lector bastaría para deshacer ambos equívocos o deficiencias; Lenz no quiso colaborar.

Segunda. Hay en verdad oraciones de una sola palabra, no equivalentes de oración, sino verdaderas oraciones. No son un "universal" del lenguaje, sino algo propio de ciertas lenguas, entre las que se cuenta el español. Sucede que hay lenguas en las que el verbo encierra en sí la expresión del sujeto pronominal; en ellas "el VERBO es una palabra que expresa sola todo un juicio independiente (sujeto y predicado) y forma una oración" (\$243) (infra 4.4.1.). Ahora bien: esto no es del todo coherente con el principio primero, aquel que formula que toda oración normal comporta dos conceptos o dos palabras sucesivas; y parece invitar a concluir que el único elemento imprescindible para constituir una oración es el verbo y solo el verbo: "sin verbo no hay oración normal, el verbo no se puede sustituir" (\$345); habría, así, oraciones normales integradas por una sola palabra, lo que casa mal con el principio primero. No representaba esto una gran novedad en 1920.

Tercera. El caso de las proposiciones incompletas y los fragmentos de proposiciones. Lenz es consciente de que "existen proposiciones 
incompletas, truncadas, que, sin embargo, podemos considerarlas como proposiciones"14 (\$15) y de que su definición de oración (supra 3.2.3) "solo podrá referirse a los casos típicos de la proposición normal". Estamos de nuevo ante proposiciones "anormales"; volvemos a los prototipos y a constatar la existencia de enunciados reales "perfectos" que no cumplen con los requisitos que les son exigidos desde la teoría; enunciados que: (i) pueden constar de una sola palabra; (ii) pueden no quedar constituidos por verbos, sino por otros tipos de palabras.

Se consideran aquí construcciones elípticas en las que, por eludir la redundancia, se ha omitido información que puede ser repuesta fácilmente -aunque no con naturalidad - toda vez que ha sido previamente mencionada (anafórica) o es deducible de la situación comunicativa en que se enuncian (deíctica). Así (los ejemplos son suyos, pp. 41-42):

A.- ¿Adónde va usted?

B.- A Valparaíso: "al decir "a Valparaíso" él piensa también: "Yo voy"” A.- ¿Ahora mismo?: "piensa: “¿Va usted ahora mismo a Valparaíso?”, pero dice solamente los elementos necesarios para completar las palabras ya dichas parte por él", parte por el otro interlocutor.

A.- Felicidades es un fragmento de proposición por "le deseo a usted muchas) felicidades"

B.- Gracias es un fragmento de proposición por "(le doy a usted las) gracias"

Todo parece de sentido común: se repone, más o menos libremente, lo que de modo intuitivo parece que falta; pero se trata en cualquier caso de elipsis ad hoc, al modo de la gramática tradicional previa: de hecho, Lenz no explica ni las condiciones que exigen o permiten la elisión, ni cómo o cuándo o por qué se puede reponer lo "perdido" (más allá de "el que dice X piensa también Y, pero no lo emite"). Ahora bien, ello no parece compatible con estas otras palabras suyas impresas tan solo un par de páginas antes:

Si bien es verdad que las palabras pronunciadas pueden acompañarse de ideas y sentimientos no expresados, sólo respecto a nosotros mismos podemos saber algo de esos elementos no expresados; en la oración ajena no podemos sino sospechar cuáles son esas "palabras subentendidas,

14 ¿En función de qué factores? Esta es, en buena medida, la cuestión: ¿por qué sí considerarlas auténticas proposiciones cuando no cumplen lo que tienen que cumplir para serlo? 
calladas o tácitas", para usar los términos del lenguaje gramatical escolar. "En todo caso - dice Wundt [...]- hay una diferencia entre el lenguaje expresado y lo que quizá acompaña a esta expresión como pensamiento callado. $\underline{\mathrm{Si} \text { se quieren determinar las cualidades de la oración }}$ en el lenguaje realmente hablado, sólo se debe tomar en cuenta lo que efectivamente se ha dicho, y no lo que tal vez se ha pensado al mismo tiempo, ni menos lo que se agrega posteriormente por interpretación lógica" $(\$ 14$, p. 40).

Sin comentarios.

Sucede, por lo demás, que [por lo menos a mí] no [me] queda claro por qué ni en qué medida estas proposiciones incompletas son proposiciones cuando: (i) no acatan la definición de oración: "descomposición de una representación en todos sus elementos", al menos dos; (ii) no contienen un juicio completo (a menos que libremente se reponga lo que plazca); (iii) son "gramaticalmente incompletas"; y (iv) "no siempre es dable completarlas gramaticalmente ni en el pensamiento": ¿qué hacer con ellas entonces? Hay algo raro aquí, algo que se [me] escapa de las manos.

Se consideran -quizá- proposiciones por esta razón: porque "no les falta nada". La pregunta ahora sería: "no les falta nada" ¿de qué?, puesto que se admite de entrada que son "incompletas"; si son "incompletas" es porque sí les falta algo. Esa carencia no parece semántica (puesto que siguen teniendo "sentido completo") ni pragmática (puesto que se descifran bien en la situación comunicativa en la que se emiten), sino gramatical. Si tal es el caso, no sería, pues, desde la gramática como se configura la unidad oracional -toda vez que sus requisitos formales pueden debilitarse o perderse-, sino desde otros supuestos. Parece que, en el fondo, la ORACIÓN no debe cumplir ningún requisito gramatical-formal; solo comunicativo-psicológico, con lo que hemos de retornar a la consideración según la cual ORACIÓN en Lenz es algo próximo, si no idéntico, a lo que ahora entendemos por enunciado: unidad mínima de comunicación y de información. Habría, en tal caso, dos tipos de oración/enunciado: los completos-normales, de más de una palabra donde todo queda expreso; y los incompletos o fragmentarios, en los que paradójicamente falta algo sin que falte nada (i) y/o que se componen de una sola palabra. Esto nos conduce al apartado siguiente.

Cuarta. El caso de las "oraciones de una sola palabra" y los equivalentes de oración. Por último: existen palabras que, aun sin ser propiamente oraciones, "sirven por sí solas como equivalentes a proposiciones" $(\S 15)$. Este asunto sí queda resuelto por el propio autor: "una palabra que es equivalente a una oración no debe considerarse como una oración, según se ha hecho comúnmente hasta hoy". Entre tales palabras se encuentran: 
(i) las que ocasionalmente equivalen a oración: los vocativos; (ii) las que siempre equivalen a oración: $s i, n o^{15}$; las interjecciones; las exclamaciones como jojo!, ;adelante!, jbravo!..., pero no los imperativos: estos no son oraciones truncadas, sino perfectas y completas, toda vez que el sujeto -inequívocamente segunda persona e inequívocamente presente en la situación $\S \S 23$ y 242) - se halla en la propia terminación verbal ${ }^{16}$; aquí sujeto y predicado se encuentran en una sola palabra ${ }^{17}$.

\subsubsection{No resulta fácil comprender cabalmente la teoría de Lenz con} respecto a la unidad lingüística oración, ni sintetizar con visos de acierto su pensamiento para hacerlo aprehensible. Se da aquí una confluencia de factores, de tradiciones y de corrientes no necesariamente compatibles por un lado; y por el otro, una voluntad de abarcarlo todo, en perspectiva general e hispánica, que exige al autor remodelar la doctrina según avanza para adaptarla al polifacetismo y la variabilidad de la lengua castellana.

Convergen aquí ideas y propuestas de ciertas corrientes de la gramática tradicional y de la teoría psicologista de Wundt junto con ideas originales de Lenz -tendentes en buena medida a rellenar lagunas y resolver problemas que sus fuentes dejaban pendientes-; con ello se aúna una fuerte atracción ejercida por lo semántico-lógico y por lo [disculpas por el anacronismo] "pragmático" (la aportación de la oración desde un punto de vista comunicativo e informativo) y un cierto desdén por los requisitos estructural-formales (de qué tiene que componerse cada entidad concreta de esta naturaleza), lo que obliga al autor a hacer ajustes -más o menos ad hoc-a los planteamientos programáticos iniciales.

\footnotetext{
15 Serían en parte las palabras de respuesta que se encuentran ya en Prisciano: "de oratione "oratio est ordinatio dictionum congrua, sententiam perfectam |demonstrans. est autem haec definitio orationis eius, quae est generalis, id est|quae in species siue partes diuiditur. nam oratio dicitur etiam liber $|0054|$ rhetoricus nec non unaquaeque dictio hoc saepe nomine nuncupatur, cum plenam|ostendit sententiam, ut uerba imperatiua et responsiua, quae saepe una dictione complentur, ut si dicam: quid est summum bonum in uita? et |respondeat quis: honestas, dico: bona oratione respondit" (en http://kaali.linguist.jussieu.fr/CGL/text. jsp?topic $=\mathrm{de} \% 20$ oratione $\% 20$ eiusque $\% 20$ partibus\&ref $=2,53,27-56,27)$.

16 Y ello hasta el punto de que con respecto a ;Ven tú! (con sujeto explícito) llega a sostener (\$23), que "sería más correcto escribir ;Ven, tú! El pronombre tú no es el sujeto de ven, sino vocativo, especie de aposición a la idea de sujeto, contenida en el imperativo" (p. 53 , nota), lo que resulta algo dudoso, toda vez que ambas son posibles, igualmente correctas y sencillamente diferentes.

17 "Se podrá tal vez dudar si esta expresión sintética de predicado y sujeto en una sola palabra corresponde a la definición de oración [...] pero no se puede decir que vendrás y ven sean oraciones incompletas o fragmentos de oración porque les falta el sujeto" ( $\S \S 22$ y 242).
} 
Tal vez el esquema que sigue no traicione en demasía el pensamiento de Lenz a este respecto: La oración es la unidad lingüística básica y el punto de partida del análisis gramatical. Por tal ha de entenderse una entidad lingüístico-fónica (o gráfica, claro) que prototípicamente acata estas dos exigencias:

(i) ser una unidad global de representación de lo que se percibe o se experimenta y se desea transmitir a otro; una especie de "unidad mínima de comunicación", un enunciado, por lo tanto.

(ii) estar compuesta por (al menos dos) elementos/palabras que guardan estrechas relaciones internas.

La restricción (ii) de arriba es prescindible; por lo tanto no es técnicamente un requisito, con lo que el único auténtico requisito es $(i)$. Desde el punto de vista de (ii), el formal-estructural, las oraciones parece que pueden ser:

1. normales-completas-perfectas:

1.1. típicas: con al menos dos palabras, una de las cuales es un verbo;

1.2. de una sola palabra: oraciones imperativas (las dos palabras componentes se encuentran fundidas en un verbo en forma imperativa; el sujeto se halla en la terminación verbal, no habría que reponerlo porque ya está ahí);

1.3. de una sola palabra: solo un verbo, esto acontece solamente en aquellas lenguas, español incluido, en las que esta clase de palabras expresa todo el juicio (sujeto y predicado); se cumple, pues, el requisito semántico-lógico-comunicativo, y serían verdaderas oraciones.

2. especiales-incompletas-fragmentarias-anormales: exigen reponer $a d$ hoc elementos elididos o perdidos o nunca enunciados (generalmente por prescindibles: todo se entiende sin que estos queden explícitos); tienen "sentido completo".

Aparte, y sin el carácter de oraciones, se encuentran los equivalentes de oraciones: vocativos, palabras de respuesta, interjecciones, exclamaciones. La pregunta ¿en qué son equivalentes a oraciones estos tipos de enunciados? debería, tal vez, ser respondida de este modo: en su significado, en su "sentido completo", en su autonomía o independencia fónica, en que constituyen, otra vez, enunciados. Ahora bien: ello vuelve a conducir a la misma conclusión: lo que importa es el requisito ( $i$ ) de arriba; en eso consiste lo oracional; las demás condiciones parecen superfluas. 


\section{4. ... Y SUS PARTES}

Las unidades (palabras) componentes de la unidad superior oracional que las integra son abordadas -clasificadas y definidas- por Lenz desde varias ópticas que entiendo complementarias (según el propio autor). De ese proceder resultan varios sistemas de clases de palabras/categorías verbales alternativos y simultáneos cuya configuración depende del punto de vista al que se atienda.

\subsection{Sistemas DE CATEGORÍAS VERBALES DE LA TRADICIÓN. REPASO HISTÓRICO}

Al principio de la obra (cap. I, pp. 35-39), Lenz dedica un parágrafo a las Definiciones antiguas de las partes de la oración: Andrés Bello (\$7) y otro a las Definiciones de la Academia Española (§8). Allí hace un breve repaso histórico de algunos sistemas de clases de palabras (y una crítica poco menos que feroz a las propuestas de Bello y de la Academia); más o menos:

\begin{tabular}{|c|c|c|c|c|}
\hline \begin{tabular}{|ll} 
DiOnisio DE \\
TRACIA
\end{tabular} & $\begin{array}{l}\text { SÁNCHEZ DE } \\
\text { LAS BROZAS }\end{array}$ & ANDRÉS BELLO & RAE-1906 & RAE-1917 \\
\hline \multirow[t]{2}{*}{ 1. nombre } & 1. nombre & 1. sustantivo & 1. sustantivo & 1. sustantivo \\
\hline & & 2. adjetivo & 2. adjetivo & 2. adjetivo \\
\hline 2. verbo & 2. verbo & 3. verbo & 3. verbo & 3. verbo \\
\hline 3. participio & 3. partícula & & 4. participio & \\
\hline 4. artículo & & & 5. artículo & 4. artículo \\
\hline 5. pronombre & & & 6. pronombre & 5. pronombre \\
\hline 6. preposición & & 4. preposición & 7. preposición & 6. preposición \\
\hline 7. adverbio & & 5. adverbio & 8. adverbio & 7. adverbio \\
\hline \multirow[t]{2}{*}{ 8. conjunción } & & 6. conjunción & 9. conjunción & 8. conjunción \\
\hline & & 7. interjección & 10. interjección & 9. interjección \\
\hline
\end{tabular}

Sostiene que "con un poco de reflexión, todo filólogo comprenderá que casi todas las definiciones enumeradas son más o menos defectuosas e insuficientes para una comprensión científica del análisis de la lengua castellana" y que buena parte del problema radica en que los gramáticos no han ofrecido previamente una "definición general de la oración". Lenz procede en consecuencia (es algo de lo que se ha tratado en los apartados 
precedentes): "soluciona" primero el concepto de oración y luego acomete su división en partes.

Es razonable admitir que las categorías con las que se constituyen capítulos autónomos del libro deben de ser muy probablemente aquellas que, a juicio de Lenz, se configuran como clases primarias de palabras/ verdaderas partes de la oración. Son a saber:
Cap. IV. Sustantivo
Cap. V. Adjetivo
Cap.VI. Adverbio
Cap. VII. Pronombre
Cap. VIII. Verbo
Cap. IX. Preposición
Cap. X. Conjunción

La cuestión pendiente es dar razón de cómo y por qué se ha llegado a esa conclusión -con la que, insisto, se configura la propia estructura del libro-y justificar por qué precisamente esas (qué se incluye) y no otras (cuáles se excluyen de las "primarias" y pasan a ser relegadas a la condición de meras subclases o subcategorías). Como Lenz sabe perfectamente, la respuesta a la pregunta “¿Cuántas son las partes de la oración?” depende "del punto de vista que se tome en cuenta para clasificar las palabras" (\$358). Y procede en consecuencia.

De entrada (§46), se plantea una gran división en dos tipos: (i) "Palabras que no son partes de la oración, porque por sí solas equivalen a oraciones" y por lo tanto no podrían formar parte componente de ella (supra 3.2.5. Cuarta); y (ii) palabras que sí son una parte de la oración constituida. Tal punto de vista tiene arraigo en la propia tradición gramatical hispánica, especialmente la conectada con la gramática general francesa (Gómez Asencio 1981) y no es, por lo tanto, una aportación de Lenz a dicha tradición.

Entre las primeras se cuentan:

(a) las "interjecciones primitivas" (también llamadas propias en la tradición), esto es, aquellas que nunca entran en el conjunto de una construcción sintáctica: son, como su nombre sugiere, inter-iectae.

(b) las "interjecciones secundarias": estas por un lado son partes de la oración en su función lingüística no traslaticia, no interjectivoexclamativa; y por el otro pierden el carácter de tales y se usan provisionalmente como equivalentes de oración (;ojo!, ;adelante!, ¡bravo!). Según sus usos, pues, son y no son partes de la oración.

(c) Los "adverbios de afirmación y de negación absoluta": sí y no como palabras de respuesta (no en creo que sí ; sí en ¿llegaremos a tiempo? / $\underline{\text { i }}$ ) Aquí Lenz apunta a la posibilidad de que en castellano existan dos no: uno equivalente a francés non, y otro a ne... pas. 
Las segundas, las partes de la oración propiamente tales, son todas las demás. A ellas se les aplican los apartados que siguen.

\subsection{El CRITERIO FORMAL: Sistema I}

Con Sánchez de la Brozas (1587) [o con Correas (1626) o con uno de los sistemas de Salvá (1835, aunque sin citarlos], considera que "formalmente bastaría en castellano y en muchas otras lenguas una clasificación en nombre, verbo y partícula ${ }^{18}$, comprendiendo con esta denominación todas las palabras invariables, cuyos deslindes son más o menos dudosos en todos los idiomas" (\$358).

Criterio: formal

Perspectiva: extraoracional, extraproposional, extradiscursiva

Resultado: tres clases de palabras (no partes de la oración):

nombre: con género y sin tiempo ni modo

verbo: sin género y con tiempo y modo

partícula: sin género, ni tiempo ni modo.

\subsection{El CRITERIO SEMÁNTICO: Sistema II}

Las palabras se clasifican también "según su significado". Esta clasificación no es particular del español, sino propia de todos los idiomas ( $\$ 46)$; pertenece, por consiguiente, a la gramática general. Se desempeña de este modo:

A. Palabras "fundamentales o primarias": "con ellas se forma lo esencial de la oración" (§46):

18 Aquí se comprenden: adverbios, preposiciones, conjunciones y "las palabras enfáticas". Entre estas últimas se cuentan elementos (palabras y locuciones) próximos a los ahora llamados operadores, marcadores o conectores discursivos: pues, con que, sin embargo, no obstante, en verdad, además, es que, sí que, verdad que, vamos, vaya, oye, mire, no más, etc. (\$41). Como se puede apreciar, constituyen una especie de cajón de sastre que admite elementos que no se ajustan con propiedad a los caracteres de las otras clases y/o que no recubren exactamente ninguna de las funciones tipificadas para las otras partes de la oración.

Parece que también se incluyen aquí algunos reforzadores y atenuadores que, en ciertas lenguas, constituyen entradas léxicas (Lenz sugiere la equivalencia de estos últimos con diminutivos afectivos del español) (pp. 72-73) (infra nota 24). 
1. Palabras que expresan conceptos (palabras conceptuales):

\begin{tabular}{|c|c|}
\hline $\begin{array}{l}\text { se clasifican según } \\
\text { las categorías lógicas de: }\end{array}$ & $\begin{array}{l}\text { les corresponden } \\
\text { las categorías gramaticales de: }\end{array}$ \\
\hline sustancia & sustantivo \\
\hline cualidad & adjetivo \\
\hline estado pasajero o fenómeno & verbo \\
\hline \multicolumn{2}{|c|}{ TABLA III. PalabRas CONCEPTUALES EN LENZ } \\
\hline
\end{tabular}

2. Palabras que repiten o reemplazan conceptos (palabras pronominales) ${ }^{19}$ : Aquí van los pronombres personales y posesivos -relación con el acto de la palabra ${ }^{20}-$ y los demostrativos, todos los cuales "no sólo repiten ideas: también las relacionan y las determinan".

Así en un lugar (§46).

En otro, en la conclusión final del libro (\$358), la información/ clasificación obediente a este mismo criterio semántico se presenta de manera diferente:

\begin{tabular}{|c|c|}
\hline \multirow{2}{*}{$\begin{array}{l}\text { sustantivos, adjetivos } \\
\mathrm{y} \text { adverbios }\end{array}$} & conceptuales: expresan directamente conceptos \\
\hline & pronominales: solamente repiten conceptos \\
\hline \multirow[b]{2}{*}{ adjetivos y adverbios } & conceptuales: que son calificativos \\
\hline & $\begin{array}{l}\text { determinativos: artículos, demostrativos, etc. y } \\
\text { cuantitativos }\end{array}$ \\
\hline \multicolumn{2}{|c|}{ Tabla IV. Otra clasificación (semántica) en Lenz } \\
\hline
\end{tabular}

Se observará:

(i) que los adverbios no se encontraban en la formulación inicial del $\S 46$, ni como palabras conceptuales ni como palabras pronominales; aparecen aquí en el resumen conclusivo final (en el §358), posiblemente a caballo entre ambas, toda vez que hay adverbios de ambos tipos (mañana, bien vs alli, entonces);

19 Origen lejano en Apolonio: nombre: designa la sustancia con sus accidentes; pronombre: designa la sustancia sin accidentes/cualidades (estas le vienen dadas por la deixis o por la anáfora). Escribe Lenz: "no expresan ningún concepto, sino que lo reemplazan; repiten un concepto antes emitido, o sustituyen uno que está determinado por el mismo acto de la palabra, o por un gesto" (\$38).

20 Idea de largo recorrido en la tradición hispánica; ya desde Nebrija (1492) (Gómez Asencio 1986). 
(ii) que se apunta la existencia de sustantivos, adjetivos y adverbios pronominales, y ello hasta el punto de que plantea la existencia de prosustantivos (yo, tú), proadjetivos ("tal hombre es un hombre de las cualidades antes indicadas o mostradas") y proadverbios (aqui 'en este lugar, donde estoy yo', etc.; entonces, cuando) $(\$ \S 38,141$, $143)$;

(iii) que, acertadamente desde nuestro punto de vista actual, se reconoce la existencia de adjetivos y adverbios conceptuales (bueno, bien) y determinativos ${ }^{21}$ (este, aquí; mucho, mucho; solo, sólo):

(iv) que en la formulación inicial, los adjetivos en tanto que clase pertenecen al grupo de las conceptuales: designan cualidades; ello hace complicado que también/a la vez puedan ser palabras determinativas, esto es, no conceptuales.

A menos, claro está, que se considere -con buena parte de la tradiciónque la clase adjetivo incluye aquellas palabras que comparten el ser términos secundarios y acompañan/concuerdan con el nombre: este criterio sería el prioritario para establecer la clase, la cual -una vez así configurada- se subdividiría en: palabras conceptuales (unos adjetivos) y palabras determinativas (no calificativas, no conceptuales: otros adjetivos diferentes). Ahora bien: esta clase se configura ad hoc, es "artificial" (infra 4.4.2. [II]).

B. Palabras [que, desde el punto de vista de la gramática general en la que se instala Lenz, podríamos denominar, por contraste con las anteriores] no-fundamentales o no-primarias (insisto: Lenz no apunta estos nombres para estos tipos):

3. Palabras que relacionan y determinan conceptos o proposiciones (palabras de relación y determinación):

Artículos, preposiciones, conjunciones "tienen algún valor, encierran algún sentido de determinación o relación” (§39), pero no expresan conceptos.

domus amici: dos palabras, dos conceptos

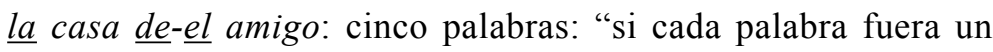

21 En lo que respecta a los adverbios determinativos, Lenz reconoce haber tomado la idea de la New English Grammar Logical and Historical (1892) de Henry SweEt (1845-1912), y el término, de la gramática académica. 
concepto, ¿cuáles son los tres conceptos que se han añadido al traducir del latín al español?"22.

La expresión de la relación gramatical y lógica puede tener lugar: (a) entre elementos de la misma proposición: preposición; (b) entre diferentes proposiciones: conjunción $n^{23}$. Y añade: "el mismo oficio tienen también las terminaciones flexivas de las palabras variables y ciertos verbos auxiliares" (final del §358), lo que inevitablemente trae a la memoria las palabras conexivas de Calleja (1818) (verbo ser, preposición, conjunción).

Se observará igualmente que hay alguna disonancia en el tratamiento de los artículos: aquí se consideran una clase de palabras del tipo 3., las que relacionan -aunque este oficio no queda nada claro- y determinan; en la tabla IV de arriba son, en cambio, incluidos entre los adjetivos y adverbios determinativos; y es que, en efecto, tienen un componente adjetivo ("va junto a...") y un componente determinativo, pero quizá Lenz debería haberles asignado solo un puesto en su sistema.

\section{Palabras que refuerzan conceptos o proposiciones:}

No se insiste demasiado en estas (tal vez porque, como sostiene Lenz, en español son escasas, frente a otras lenguas en donde abundan), pero parece que se trata de las en otro lugar llamadas palabras enfáticas. Sirven para reforzar o disminuir el valor de todo lo dicho (\$350), y entre ellas -con fina precisión descriptiva- se incluye la palabra seguramente ${ }^{24}$, a la que Lenz atribuye dos valores-funciones:

(a) "simple complemento ordinario", que modifica la acción del verbo: adverbio:

22 "Si en castellano admitimos que preposiciones y conjunciones son gramaticalmente palabras por su relativa independencia, lógicamente no lo son. Lo mismo se puede decir de los artículos" (pp. 71-72). En otros idiomas eso mismo se expresa por medio de terminaciones, sufijos, prefijos, etc. Se presenta aquí el mismo tipo de presión logicista que llevó a Lenz a afirmar (§150): el verbo "lógicamente no es una palabra, sino la composición de dos: la expresión del fenómeno y la del sujeto [...]" (la cursiva es suya).

23 Para la cuestión de qué elementos quedan unidos por medio de las conjunciones, véase ahora Gómez Asencio y Martín Gallego 2014.

${ }^{24} \mathrm{O}$ ¿verdad?, ¿no? en su valor de "question tags" cuando se emplean, por ejemplo, para pedir la aprobación del interlocutor. Son asimismo (partículas) enfáticas aquél (vs. él), muy (¿en su carácter de intensificador equivalente a-isimo?) etc. (supra nota 18). 
Usted puede pasar seguramente por este puente: 'con seguridad, sin peligro'

(b) "palabra enfática", que "indica una relación vaga con lo que se ha dicho con anterioridad": "adverbio oracional" (modifica "a la oración entera" [\$140]):

Seguramente usted ha pasado por este puente: 'yo estoy seguro de que usted...'

Criterio: lógico-semántico

Perspectiva: extraoracional, extraproposional, extradiscursiva.

Resultado: cuatro clases de palabras (no partes de la oración):

expresan conceptos: sustantivos, adjetivos, verbos, ¿adverbios? repiten o reemplazan conceptos: pronombres.

relacionan o determinan conceptos: artículos, preposiciones, conjunciones.

refuerzan conceptos: palabras enfáticas (entre ellas algunos adverbios).

\subsection{El CRITERIO FUnCIONAL: Sistema III}

Parece el factor fundamental en la consideración de Lenz, el clave en la categorización de las entradas léxicas de una lengua; al menos esto es lo que él insiste en afirmar:

Para el análisis gramatical del idioma, lo que más importa es la clasificación de las palabras según su función como "parte de la oración", de la cual se separan sólo mediante especulaciones científicas (§358).

Y sigue:

Según la función gramatical, en castellano se deben distinguir las siguientes partes de la oración; $1^{\mathrm{a}}$, el substantivo; $2^{\mathrm{a}}$, el adjetivo; $3^{\mathrm{a}}$, el verbo; $4^{\mathrm{a}}$, el adverbio; $5^{\mathrm{a}}$, la preposición; $6^{\mathrm{a}}$, la conjunción (incluyendo las palabras enfáticas, poco numerosas) (idem).

Criterio: sintáctico-funcional

Perspectiva: intraoracional, intraproposional, intradiscursiva

Resultado: seis partes de la oración (no clases de palabras) 
De entrada se observará que, tanto con respecto a las cuatro grandes clases ("metaclases") analizadas en 4.3., como en relación con la lista de los capítulos de la obra (supra 4.1.), han desaparecido los pronombres, renuentes - como es de todos sabido- a someterse al criterio funcional, según el cual están condenados a confundirse con los sustantivos (o con otras clases) (infra nota 29); y -ahora solo en cotejo con 4.3.- también las palabras enfáticas ${ }^{25}$, difíciles de acomodar a las funciones intra-oracionales o inter-oracionales más comunes y tipificadas en la época. Dicho de otro modo: según la aplicación del criterio funcional por parte de Lenz, ni los pronombres (o, por decirlo mejor, las palabras pronominales) ni las palabras enfáticas ni los artículos -de los que se hace caso omiso en este punto- son partes de la oración, no son categorías verbales funcionales; esto es: la mitad de las clases semántico-lógicas de palabras expuestas en 4.3. se ha quedado fuera al aplicar el nuevo criterio.

\subsubsection{Lenz vs. Bello}

La información extractada más relevante se encuentra en la siguiente tabla (los números romanos entre corchetes remiten a comentarios que se introducirán más adelante en 4.4.2.).

\begin{tabular}{|l|l|l|}
\hline & $\begin{array}{l}\text { A. BELLO-1847 } \\
\text { clases de palabras } \\
\text { por sus oficios }\end{array}$ & $\begin{array}{l}\text { R. LENZ-1920 } \\
\text { partes de la oración } \\
\text { [por su función] }\end{array}$ \\
\hline $\begin{array}{l}\text { 1. } \\
\text { sustantivo } \\
{[\mathrm{I}]}\end{array}$ & $\begin{array}{l}\text { palabra que puede servir } \\
\text { para designar el sujeto } \\
\text { de la proposición }\end{array}$ & $\begin{array}{l}\text { palabra que sirve de sujeto activo } \\
\text { o pasivo de una proposición }\end{array}$ \\
\hline $\begin{array}{l}2 . \text { adjetivo } \\
{[\mathrm{II}]}\end{array}$ & $\begin{array}{l}\text { se refiere al sustantivo y lo } \\
\text { modifica directamente. } \\
\text { se llama adjetivo porque } \\
\text { suele añadirse al sustantivo }\end{array}$ & $\begin{array}{l}\text { palabra variable que modifica } \\
\text { o determina a un sustantivo, } \\
\text { sea como atributo inmediato } \\
\text { o como atributo predicativo }\end{array}$ \\
\hline
\end{tabular}

25 Aunque, de facto, sí que se alude a ellas entre paréntesis e incluyéndolas en la clase conjunción (a pesar de que la función y su naturaleza de unas y de otras son diferentes; y de que muchas de ellas caben bien bajo los adverbios y poco bien bajo las conjunciones; supra 4.3.B.4.). 


\begin{tabular}{|c|c|c|}
\hline $\begin{array}{l}\text { 3. verbo } \\
\text { [III] }\end{array}$ & $\begin{array}{l}\text { palabra que denota el atributo } \\
\text { de la proposición, indicando } \\
\text { juntamente el número y } \\
\text { persona del sujeto y el tiempo } \\
\text { del mismo atributo }{ }^{26}\end{array}$ & $\begin{array}{l}1^{\circ} \text {. [el verbo encierra en sí } \\
\text { la expresión clara del sujeto } \\
\text { pronominal] Palabra que } \\
\text { sola expresa todo un juicio } \\
\text { independiente (sujeto y } \\
\text { predicado) y forma una oración } \\
2^{o} \text {. [se exige la expresión } \\
\text { separada del sujeto] Palabra } \\
\text { que, añadida a un sujeto, } \\
\text { expresa con él un juicio } \\
\text { completo e independiente } \\
\text { y forma una oración }\end{array}$ \\
\hline $\begin{array}{l}\text { 4. adverbio } \\
\text { [IV] }\end{array}$ & $\begin{array}{l}\text { modifica al verbo y al adjetivo } \\
{[\ldots] \text { y a otro adverbio }}\end{array}$ & $\begin{array}{l}\text { palabra invariable que sirve } \\
\text { para modificar o determinar } \\
\text { al verbo o a cualquier palabra } \\
\text { calificativa. También puede } \\
\text { modificar a la oración entera }\end{array}$ \\
\hline $\begin{array}{l}5 . \\
\text { preposición } \\
{[\mathrm{V}]}\end{array}$ & $\begin{array}{l}\text { su oficio es anunciar el } \\
\text { término }{ }^{27}, \text { expresando } \\
\text { también a veces la especie } \\
\text { de relación de que se trata } \\
(d e, a, e n, \text { sobre, con })\end{array}$ & $\begin{array}{l}\text { palabra invariable que } \\
\text { sirve para transformar un } \\
\text { sustantivo en atributo }{ }^{28} \mathrm{o} \\
\text { complemento de otro elemento } \\
\text { de la misma proposición }\end{array}$ \\
\hline $\begin{array}{l}6 . \\
\text { conjunción } \\
{[\mathrm{VI}] \mathrm{y}[\mathrm{VII}]}\end{array}$ & $\begin{array}{l}\text { sirve para ligar dos o más } \\
\text { palabras o frases análogas, } \\
\text { que ocupan el mismo } \\
\text { lugar en el razonamiento, } \\
\text { o proposiciones enteras }\end{array}$ & $\begin{array}{l}\text { palabra invariable que sirve } \\
\text { para expresar la relación } \\
\text { gramatical y lógica entre dos } \\
\text { proposiciones o entre dos } \\
\text { "elementos análogos" de una } \\
\text { oración ensanchada o contraída. } \\
\text { Esta relación puede ser de } \\
\text { coordinación o de subordinación }\end{array}$ \\
\hline
\end{tabular}

26 No hace falta insistir ahora otra vez en que Bello llama atributo a lo que todo el mundo llama predicado.

27 Y término (tres líneas más arriba): palabra o frase que designa el objeto, la idea en que termina una relación: un libro de Iriarte.

28 Aquí atributo debe ser entendido como 'complemento de otro elemento'. En $\S 49$ se lee: atributo adnominal (el sustantivo modifica al sustantivo; caso genitivo), atributo adverbal (el sustantivo, introducido por preposición, modifica a sustantivos, adjetivos, adverbios o verbos).

Véanse también $\$ \S 78$ y 88: "la palabra atributo se refiere a la función gramatical del adjetivo al lado del substantivo (el buen hombre, la casa grande [...] También se puede decir: grande en la casa grande es "adjetivo atributivo"; en la casa es grande, "adjetivo predicativo"”. 


\begin{tabular}{|c|c|c|}
\hline $\begin{array}{l}7 . \\
\text { interjección } \\
\text { [VIII] }\end{array}$ & $\begin{array}{l}\text { palabra en que parece hacernos } \\
\text { prorrumpir una súbita emoción o } \\
\text { afecto, cortando a menudo el hilo } \\
\text { de la oración }\end{array}$ & \\
\hline $\begin{array}{l}. \\
\text { pronombre } \\
{[\mathrm{IX}]}\end{array}$ & & $\begin{array}{l}\text { palabra que no expresa por sí } \\
\text { un concepto determinado, sino } \\
\text { que reproduce formalmente } \\
\text { (repite-reemplaza) un concepto } \\
\text { antes emitido, o indica un } \\
\text { concepto determinado por el } \\
\text { mismo acto de la palabra o } \\
\text { por una acción (un gesto) que } \\
\text { acompaña al acto de la palabra }\end{array}$ \\
\hline Interjección & & $\begin{array}{l}\text { Equivalente (no parte) } \\
\text { de oración. } \\
\text { No entra en el conjunto de } \\
\text { una construcción sintáctica. } \\
\text { No entra en relación gramatical } \\
\text { con otras palabras }\end{array}$ \\
\hline Pronombre & $\begin{array}{l}\text { Llamamos pronombres los } \\
\text { nombres que significan primera, } \\
\text { segunda o tercera persona, } \\
\text { ya expresen esta sola idea } \\
\text { [personales], ya la asocien con } \\
\text { otra [posesivos, demostrativos] }]^{29} \text {. }\end{array}$ & \\
\hline
\end{tabular}

Bello entiende que son siete las clases de palabras "por sus varios oficios": incluye la interjección (de modo poco convincente, dado que no se explica qué función sintáctica intraoracional podría desempeñar) y excluye el pronombre (esto sí con argumentos poderosos: hacen el mismo trabajo en

29 Son, pues, para Bello una subclase de los nombres. Sigue la argumentación en la Nota IV: "El pronombre, a semejanza del nombre, se divide en sustantivo y adjetivo; tiene género y número como el nombre; se declina (dicen) como el nombre; no le falta, en suma, ninguno de los oficios y caracteres de los nombres [...] No comprendo cómo han podido colocarse el nombre y el pronombre en categorías diversas". En todo caso sería "una especie particular de sustantivo o de adjetivo, no una parte de la oración distinta de ellos" (supra 4.4.). 
la oración que sustantivos y adjetivos; no son, pues, una parte funcional autónoma de la oración; véase la nota 29).

Para Lenz también son siete las "partes de la oración", pero a diferencia de Bello, excluye la interjección (esto sí con argumentos convincentes, ya en boga desde antes del siglo XIX: no concurren dentro de una oración, van exentas, deslavazadas, inconexas), y, a medias, incluye el pronombre. Con ese "a medias" me refiero a lo siguiente. No resulta fácil determinar qué estatus confiere Lenz a esta categoría verbal: (i) por un lado, en la medida en que no tiene una función sintáctica que le sea propia y exclusiva -y esto es lo más importante para nuestro autor-, no constituye una parte funcional de la oración (vid. cita del $\$ 358$ mencionada más arriba en 4.4.); (ii) pero, por otro, sí que la cuenta en la lista de las categorías que va examinando capítulo tras capítulo a lo largo del libro (lista idealmente constituida desde la perspectiva funcional, que no se respetaría en este caso; supra 4.1.); la ubica en el Cap. VII tras sustantivo, adjetivo y adverbio (y antes del verbo), lo que tal vez guarde relación con el hecho de que Lenz entiende que más que de pronombres propiamente tales debería postularse, por su trabajo intraoracional, la existencia de prosustantivos (yo, tú, él, ella, éste, alguien, algo...), proadjetivos (tal, algún, cada, todo, este... $)^{30}$ o proadverbios (asi ${ }^{31}$, aqui, tan, cómo, como, cuando, cuándo...) según su función sintáctica ( $\S \S 38,155$ o 208$)$; este enfoque permitiría aventurar una interpretación del ¿aparentemente incoherente? proceder de Lenz respecto al pronombre: serían pronombres las palabras de naturaleza deíctica o anafórica; tales

30 Se debe reparar, no obstante, en que la naturaleza de estos no es transparente ni queda claramente configurada. Así, mientras que los llamados prosustantivos sí que -en algún sentido- son sustitutos (pro) de nombres (ella, éste), no parece que todos los proadjetivos lo sean de adjetivos, que es lo que Lenz confirma (\$208). En efecto: se podría aceptar que tal en Un hombre alto y con bigote; tal hombre... sí reproduce conceptos, en este caso cualidades antes mencionadas del hombre en cuestión; pero algún o cada en algún gato, cada persona no parece ni que reemplacen ( $p r o$ ) a ningún adjetivo -anáfora-, ni que indiquen un concepto (cualidad) determinado por el mismo acto de la palabra -deixis-; más bien, trabajan como adjetivos.

Habría, pues, pronombres sustantivos, pronombres adjetivos, pronombres adverbios, en el sentido de "palabra anafórica o deíctica que en la oración hace lo mismo que, respectivamente, un sustantivo, un adjetivo o un adverbio; suple alguna de esas funciones'. Habría que postular que los pronombres se caracterizan por ser palabras vacías de función oracional específica que, según y cómo, adoptan el papel de un sustantivo, un adjetivo o un adverbio. Ahora bien: este tipo de "función" es diferente del que se tiene en cuenta a la hora de definir el resto de las partes de la oración.

31 "Así, proadverbio demostrativo de modo, que se puede referir a cualidades o a circunstancias, pero en sí no dice (no califica) nada, sino que repite y sustituye el concepto antes emitido o demostrado" $(\S 141)$. 
palabras, por su función sintáctica propiamente dicha, hacen de sustantivos, de adjetivos o de adverbios ${ }^{32}$.

Ambos autores, pues, reconocen las categorías verbales que se encuentran en la tabla V. de arriba, pero desde consideraciones diferentes: comparten las seis primeras; discrepan en que según Bello, el pronombre sí es una categoría verbal (en realidad: una subclase de los nombres ${ }^{33}$ ), pero no una clase de palabras por su oficio, no es una categoría funcional de la oración; y según Lenz, la interjección sí es una categoría verbal, pero no una parte de la oración (equivalente de oración).

\subsubsection{Comentarios numerados a la tabla del 4.4.1.}

[I] No es fácil entender por qué Lenz afea esta definición de Bello: "en el substantivo ya flaquea la definición [de Bello] por un "puede" que le parece inevitable al autor" (§7). En efecto, puede viene ahí a significar 'es susceptible por sí solo' de ejercer ese oficio, algo que lo caracteriza, lo aísla y lo define. Y se entiende menos si se comprueba que Bello, inmediatamente después de lo transcrito en la tabla V, añade: "Se dice que puede servir, no que sirve, porque, además de esta función, el sustantivo ejerce otras" ${ }^{34}$.

Por otro lado: en términos estrictos, la especificación de si el sustantivo oficia de sujeto "activo o pasivo" es redundante e irrelevante en una definición; con "sujeto" habría sido suficiente, sin enumeración explícita de los tipos de sujeto (vid infra comentario [VII]).

[II] Tampoco se muestra precisamente generoso Lenz en su comentario respecto al adjetivo en Bello:

32 Sucede, para terminar, que en lo sustancial, los proadjetivos y los proadverbios coinciden con, respectivamente, los adjetivos determinativos y los adverbios determinativos, esto es, los no conceptuales, con lo que las categorías se solapan y habría entradas léxicas que figurarían en varias casillas a la vez (tal: adjetivo por una cosa y pronombre por otra cosa; así: adverbio y pronombre).

33 Que, como es bien sabido, no constituyen una parte de la oración para Bello, quien separa con nitidez y por su función sustantivos de adjetivos. Así, acepta que hay (al modo de Correas 1626) pronombres sustantivos y pronombres adjetivos, según que hagan los oficios de una o de otra partes funcionales de la oración.

34 Para las funciones del sustantivo en Lenz (coincidentes, como no podía ser de otro modo, con las de Bello), cfr. §49. 
Bello se contenta con esta explicación: "Llámanse adjetivos porque suelen añadirse al substantivo". Respecto a su función, sólo dice que modifican al substantivo, se refieren a él y lo modifican directamente [sic].

No entiendo a qué viene ese se contenta (de hecho, Bello no se contenta: dice más cosas) o ese solo en la cita de Lenz: esa es la función del adjetivo, aquella con la que Bello ha decidido caracterizarlo y distinguirlo de las otras partes de la oración.

De todos modos, es más que probable que tales críticas tengan que ver con que Bello no explicita también que el adjetivo "determina"; eso -a juicio de Lenz- es crucial para delimitar la categoría adjetivo, entre otras razones porque es el único modo de permitir que los llamados "determinantes" (que no modifican) puedan ser incluidos en la clase de los adjetivos ${ }^{35} \mathrm{y}$ de consentir, tácitamente, la convivencia de dos subclases en la categoría de los adjetivos ${ }^{36}$.

Ahora bien: ( $i$ ) da la sensación de que en su descripción funcional de la clase adjetivo Lenz no define propiamente la clase como tal; antes bien, parece como si la definición hubiera sido concebida de antemano como la suma de las definiciones de las dos subclases que, a priori, se tenía determinado incluir bajo ella: cuando se afirma que el adjetivo "modifica o determina" no se está diciendo -en nuestra interpretación- que 'todos los adjetivos hacen ambas cosas según circunstancias', sino esto otro: 'unos modifican, otros determinan'. De ser así, la clave definitoria de la clase no sería sintáctico-funcional (de hecho, se contienen dos funciones sintáctico-semánticas diferentes ahí: la calificativa y la determinativa); sería sintáctico-colocacional: su carácter de adyacente del sustantivo, el hecho combinatorio de que se añade al sustantivo es lo que caracterizaría al adjetivo, ello en la más pura línea tradicional y "etimológica" (ad-iectivum) $)^{37}$; y (ii) la cuestión no constituye un problema en la teoría bellista: los "adjetivos determinativos" de Lenz no son tales adjetivos en Bello;

35 Abunda en esa interpretación esta otra cita de Lenz: "En la enseñanza gramatical en Chile se suele decir simplemente que en las frases "un buen niño" o "el niño enfermo", el adjetivo modifica al substantivo, término inconveniente cuando se trata de adjetivos como mucho, este, etc." (p. 29 nota 1).

36 Subclases bien diferentes, por cierto, y frecuentemente llamadas adjetivos calificativos y determinativos.

37 Cfr. supra 4.3.A.2. Allí se plantea la "dificultad" de que la clase adjetivo esté constituida al tiempo por palabras conceptuales $=$ calificativas y por palabras no-conceptuales $=$ determinativas. 
son "pronombres en combinatoria adjetival" (aquella casa, su auto); no es, por lo tanto, que Bello "se contente" con poco, es que reubica las categorías.

[III] Se recordará que Lenz escribe un libro de gramática general y castellana. Sus referencias al lenguaje, a todas las lenguas, a familias de lenguas, etc. son constantes a lo largo del texto; solo desde ahí se comprende la doble definición de la categoría verbo: una para las lenguas que, como el español o el latín, no necesitan de sujeto pronominal porque este es "visible" al estar comprendido en la desinencia verbal; otra para las lenguas que, como el francés o el inglés, exigen la expresión explícita del sujeto porque la desinencia verbal no lo trasluce. En verdad, para una gramática particular del español la definición primera habría sido suficiente; más o menos: verbo: "palabra que por sí sola forma ${ }^{38}$ una oración e incluye sujeto y predicado" 39 .

[Iv] Cuando Lenz se ocupa de esta propuesta bellista, solo recoge la primera parte ("modifica al verbo y al adjetivo"); no así la segunda ("y a otro adverbio"), que se encuentra en el mismo párrafo tras los ejemplos, solo unas pocas líneas más abajo. Es, en esencia, lo que se contiene en la definición de Lenz: "al verbo" y "a cualquier palabra calificativa": léase "adjetivos y adverbios".

No se encuentra en la formulación de Bello, y debe ser considerado un acierto/hallazgo de Lenz, el añadido de que el adverbio también puede afectar a una oración entera.

[v] Tampoco esto le gusta a Lenz: "En cuanto a la preposición, [Bello] da una explicación poco satisfactoria". No desvela, sin embargo, el motivo de su insatisfacción.

[vI] "Bello se aparta de la definición común, limitando el nombre a las llamadas conjunciones coordinantes", escribe Lenz. Fue, en efecto, una innovación de Bello perfectamente justificada internamente por él mismo, quien entendió que muchas de las palabras tradicionalmente consideradas conjunciones no eran sino adverbios (relativos). Lenz solo lo anota, no juzga en este caso.

[VII] El hecho de explicitar que la relación expresada por medio de una conjunción puede ser de coordinación o de subordinación -lo que consabido $\mathrm{y} / \mathrm{o}$ haya sido previamente mencionado. 
resulta irrelevante en una definición de la categoría (vid. supra comentario [I] a sustantivo) - tal vez deba de ser interpretado como una especie de advertencia anti-Bello ${ }^{40}$ : las conjunciones pueden unir elementos análogos (Bello) o elementos que no lo sean (¡ojo!: no siga usted a Bello en este asunto).

[VIII] Lenz, de nuevo, se limita a transcribir la definición bellista, sin hacer comentarios. Pero elude traer esta otra cita de Bello ${ }^{41}$ : la interjección "es como un verbo inconjugable, que envuelve el sujeto, y está siempre en la primera persona del presente de indicativo".

[IX] Bello había dejado fuera del sistema de partes de la oración por sus oficios al pronombre; razones "funcionales", desde luego, no le faltaban: son una especie de "nombres" -a la antigua usanza- que tienen función ora sustantiva (autónoma) ora adjetiva (dependiente) y se caracterizan, en la teoría bellista, porque llevan incluida una referencia a la persona gramatical $\left(1^{\mathrm{a}}, 2^{\mathrm{a}}, 3^{\mathrm{a}}\right)^{42}$. Así las cosas, no son una parte funcional de la oración con un oficio propio, toda vez que hace los oficios sintáctico-oracionales reservados a y definitorios de sustantivo o adjetivo, aunque sí una clase de palabras, bien peculiar por lo demás.

Las teorías acerca del pronombre desarrolladas por la tradición occidental son variadas y complejas, lo que en buena parte se explica por la propia complejidad de la categoría. También lo es la que configura Lenz en el texto que nos ocupa. Se entenderá que no podamos ocuparnos de ella con el detalle que merece (en sus fuentes, su capacidad descriptiva, su originalidad, su coherencia, su adecuación, su desarrollo interno, etc.), como sería nuestro interés, en este trabajo de conjunto. Solo podremos esbozar unos trazos.

Primero. En nota al pie ( $\$ 154$, p. 239$)$ tras "palabra que no expresa por sí un concepto determinado, sino que reproduce formalmente (repite-reemplaza) un concepto antes emitido" añade este comentario, seguramente destinado a neutralizar eventuales críticas previstas por el propio Lenz: "En los interrogativos e

\footnotetext{
40 Obsérvese, de paso, cómo en el propio texto de Lenz la expresión "elementos análogos" va entrecomillada.

${ }^{41}$ Inserta en la Nota I. Clasificación de las palabras, que sí que menciona explícitamente Lenz.

42 La idea ya en Nebrija: "pronombre es una delas diez partes dela oracion: la qual se declina por casos $\tau$ tiene personas determinadas"; primitivos: $y o$, tú, él; derivados: $m i, t u, s u$ (1492: III:8).
} 
indefinidos el concepto a menudo sólo ha sido pensado, no emitido, por el que habla". Podría deducirse que el pronombre como categoría reproduce un concepto emitido antes... o no emitido antes, lo que no resulta del todo convincente ${ }^{43}$ (ello sin tomar en consideración el hecho de que no queda claro en qué modo tales conceptos [por los que se pregunta o que quedan por definir] han podido ser pensados por el hablante).

Segundo. Si se observa con atención, en la definición del pronombre se van ofreciendo alternativas sucesivamente:

(i) reproduce un concepto antes emitido: sería el caso de los pronombres sustantivos, esto es, de la función sustantiva primaria y anafórica de posesivos, demostrativos, relativos.

(ii) o reproduce un concepto no emitido antes, pero sí pensado por el que habla: interrogativos e indefinidos (es de suponer que en función sustantiva primaria): ¿qué [cosa] quieres?, ¿cuántos [académicos] vinieron? (los ejemplos son míos); alguien, nadie, algo, nada, etc.

(iii) o no reproduce un concepto emitido ni no emitido, sino que indica un concepto determinado por el mismo acto de la palabra: es de suponer que se está pensando en personales y posesivos ¿y demostrativos?

(iv) o no reproduce un concepto emitido ni no emitido, y no indica un concepto determinado por el acto de la palabra, sino un concepto determinado por un gesto que acompaña [o no, podría añadirse] al acto de la palabra: se debe de estar pensando ahora en los demostrativos en pura función deíctica.

Se reparará en que, según y cómo, los demostrativos caben en casi todas las casillas; y en que la definición está construida no por identificación de un rasgo propio de la clase entera (a menos que por tal se considere el semántico-pragmático de no expresar un concepto determinado ${ }^{44}$ ), sino por acumulación de rasgos posibles, como un cajón de sastre en el que tengan cabida las diversas subclases del pronombre que se van a ir considerando después a lo largo del texto

\footnotetext{
43 Ni acaba de acompasarse con la crítica que Lenz hizo a la definición de sustantivo en Bello por aquel "puede servir..." (supra 3.2.5. Primera).

${ }_{44}$ Con lo que se retorna al espíritu de Apolonio (supra nota 19): el pronombre denota un concepto vacío de cualidades, las cuales le vienen dadas o bien porque por medio del pronombre se recuerda/retoma algo previamente mencionado, o bien por la deixis situacional o gestual, que permite identificar tales rasgos porque los ofrece "a los ojos".
} 
(personales, posesivos, demostrativos...), o las diversas maneras de aparición de las palabras concretas incluidas en la clase (términos primarios o secundarios o terciarios; fóricos o deícticos).

4.4.3. La relación entre las categorías tradicionales y los tres sistemas de Lenz

La tabla VI ha sido ideada con la finalidad de poner en relación uno de los sistemas de clases de palabras de la tradición presentados por Lenz ( $\$ \$ 7 \mathrm{y}$ 8; supra 4.1.), concretamente el que más clases proponía (el de diez), con los tres sistemas de Lenz que se han venido comentando en las páginas precedentes. La tabla habla por sí misma y exime de mayores comentarios. Invitamos al lector a examinarla en su detalle.

\begin{tabular}{|c|c|c|c|}
\hline $\begin{array}{l}\text { Sistema } \\
\text { tradicional de } \\
10 \text { clases }\end{array}$ & $\begin{array}{l}\text { Sistema I: } \\
\text { criterio } \\
\text { formal } \\
\end{array}$ & $\begin{array}{l}\text { Sistema II: } \\
\text { criterio semántico-lógico }\end{array}$ & $\begin{array}{l}\text { Sistema III: } \\
\text { criterio } \\
\text { funcional }\end{array}$ \\
\hline Interjección & \multicolumn{3}{|c|}{ Palabras que No son partes de la oración: equivalen a oración } \\
\hline - & \multicolumn{3}{|c|}{ Palabras que sí son partes de la oración } \\
\hline Sustantivo & \multirow{2}{*}{ Nombre } & \multirow{3}{*}{ Palabras conceptuales } & Sustantivo \\
\hline Adjetivo & & & Adjetivo \\
\hline$\frac{\text { Verbo }}{\text { Particinio }}$ & Verbo & & Verbo \\
\hline Pronombre & - & Palabras pronominales & ??? \\
\hline Adverbio & \multirow{3}{*}{ Partícula } & $\begin{array}{l}? ? ? \text { (¿conceptuales?/ } \\
\text { ¿pronominales?) }\end{array}$ & Adverbio \\
\hline Preposición & & \multirow{3}{*}{$\begin{array}{l}\text { Palabras relacionales } \\
\text { de conceptos }\end{array}$} & Preposición \\
\hline Conjunción & & & Conjunción \\
\hline Artículo & - & & - \\
\hline 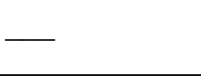 & - & $\begin{array}{l}\text { Palabras reforzadoras } \\
\text { de conceptos }\end{array}$ & \\
\hline & & $\begin{array}{l}\text { tradicional y los tres } \\
\text { las verbales de Lenz }\end{array}$ & \\
\hline
\end{tabular}

La tabla permite cotejar todos los sistemas; establecer la correspondencia entre diez de las clases de palabras tradicionales con las que Lenz va proponiendo en cada uno de sus tres sistemas; detectar la reubicación de unas y de otras -la mayor parte constantes- en los diferentes sistemas; observar algunas de las "carencias" -muchas de ellas ya glosadas previamente- en los trasvases categoriales de un sistema a otro dentro de la obra que aquí interesa: por ejemplo, qué pasa con los pronombres en el Sistema III-funcional, qué sucede con los adverbios en el Sistema II-semántico, qué acontece con las 
palabras reforzadoras de conceptos fuera del Sistema II-semántico, qué hace el artículo dentro de las palabras relacionales y dónde se ubica en el Sistema III-funcional, etc.

Permite también esta tabla VI en su conjunto forjarse una idea del inmenso esfuerzo categorizador de Lenz; de la complejidad por él asumida de abordar las categorías verbales desde tres criterios distintos que lo conducen a tres sistemas alternativos y complementarios de clases de palabras y/o de partes de la oración; de su voluntad renovadora de las ideas gramaticales o de su necesidad de distanciarse de la tradición, aun tomándola en cuenta, con el claro propósito de "mejorarla"; o del acierto indudable de muchas de sus reflexiones, si no de todas; y ello con independencia de su éxito. Y, desde luego, de la innovación y del aire fresco que este pensamiento supuso no ya en la historiografía de la gramaticografía chilena en concreto, sino hispánica en general.

\section{FINAL}

Con este trabajo se ha pretendido sacar a la luz, desentrañar e interpretar en perspectiva historiográfica algunas de las ideas de Rodolfo Lenz (1920) relativas a la categorización verbal. Previamente, se ha tratado de la equivocidad de categoría en gramática (clases léxicas, rasgos gramaticales, relaciones) (2.1.), se ha ofrecido una herramienta de interpretación y análisis de las categorías verbales (2.2.), y se ha defendido la conveniencia de distinguir con nitidez los significados y los referentes de clases de palabras vs. partes de la oración en tanto que términos técnicos o instrumentos analíticos de ciertas entidades lingüísticas (2.3.); aquí se han presentado los puntos de vista de Lenz al respecto (2.3.3.).

Como punto de partida para la cabal comprensión de las categorías verbales en este autor, se ha examinado su posicionamiento en lo relativo a la oración como unidad lingüística fundamental y en tanto que marco en el que tienen lugar las relaciones entre los elementos, sean estos léxicos o no (prefijos, desinencias, etc.) (3.2.). Tal posicionamiento justifica y sustenta el propio título de la obra: La oración y sus partes. Se ha explorado su punto de vista en torno a esa unidad oración, más escorado hacia lo semántico-comunicativo que hacia lo estructural-formal, y se ha tratado de valorar cómo oración en Lenz es algo muy próximo, cuando no idéntico, a enunciado en buena parte de la lingüística contemporánea: unidad mínima 
de comunicación dotada, en perspectiva semántico-pragmática, de un sentido completo y concreto (3.2.2. y 3.2.3.). Se han sondeado después algunos asuntos que deja pendientes o abiertos la teoría oracional elaborada por Lenz: oraciones normales vs. no-normales, oraciones de una sola palabra, oraciones incompletas o fragmentarias, elipsis $a d h o c$, entidades equivalentes de oración (3.2.5.). Finalmente, se ha presentado en 3.2.6. un resumen conclusivo de aquello en lo que hemos entendido que consiste la teoría de la oración de Lenz y su eventual desarrollo.

El trabajo se ha centrado posteriormente en las categorías verbales (partes de la oración o clases de palabras) (4.). Aquí se ha esbozado el repaso histórico que el propio Lenz hizo al respecto (4.1.); y se han analizado en perspectiva interpretativa y crítica los tres sistemas alternativos y complementarios de categorías verbales que Lenz defiende mediante la aplicación de criterios definitorios alternativos: formal (4.2), semántico-lógico (4.3.) y funcional (4.4.). Con respecto a este último -claramente el prioritario en el entender de nuestro autor- se ha cotejado su sistema con el, igualmente funcional, elaborado por Bello en 1847 (4.4.1.), y se han comentado con cierto grado de detalle los aspectos más sobresalientes que esa comparación suscita (4.4.2.). Finalmente, se ha exhibido en 4.4.3. un resumen conclusivo de los tres sistemas de Lenz confrontados entre sí y con el sistema de diez clases de palabras de la gramática tradicional, y se ha tratado de valorar la importante aportación de Lenz.

REFERENCIAS BIBLIOGRÁFICAS

EDICIONES CONSULTADAS

Lenz, Rodolfo. 1920. La oración y sus partes. Madrid: Publicaciones de la Revista de Filología Española. Junta para ampliación de estudios e investigaciones científicas. Centro de estudios históricos. Establecimiento tipográfico de Fortanet.

1925. La oración y sus partes. Estudios de gramática general y castellana. Segunda edición. Madrid: Publicaciones de la Revista de Filología Española. Junta para ampliación de estudios e investigaciones científicas. Centro de estudios históricos. Tip. de la "Revista de Archivos".

1935. La oración y sus partes. Estudios de gramática general y castellana. Tercera edición. Ávila: Publicaciones de la Revista de Filología Española. Junta para ampliación de estudios e investigaciones científicas. Centro de estudios históricos.

1944. La oración y sus partes. Estudios de gramática general y castellana. Cuarta edición. Santiago de Chile: Editorial Nascimento. [Al cuidado del P. Alfonso M. Escudero]. 


\section{BiBLIOGRAFÍA}

Escudero, Alfonso M. 1963. Rodolfo Lenz. Thesaurus XVIII(2): 445-484.

Gómez Asencio, José J. 1981. Gramática y categorías verbales en la tradición española (1771-1847). Salamanca: Universidad de Salamanca.

1986. Subclases de palabras en la tradición española (1771-1847). Salamanca: Universidad de Salamanca.

2014a. Tratamientos de la sintaxis en gramáticas españolas del último tercio del siglo XVIII. En Sylvie Archaimbault, Jean-Marie Fournier et Valérie Raby (dirs.). Penser l'histoire des savoirs linguistiques. Études épistémologiques, historiques et linguistiques en hommage à Sylvain Auroux. Lyon: ENS, pp. 393-406.

2014b. La sintaxis en gramáticas españolas de 1770 a 1854: tratamientos, modelos y ámbitos de estudio. En Félix San Vicente, Ana Lourdes de Hériz y María Enriqueta Pérez Vázquez (eds.). Perfiles para la historia y crítica de la gramática del español en Italia: siglos XIX y XX. Confluencia y cruces de tradiciones gramaticográficas. Bolonia: BUP, pp. 61-92.

2015a. Unidades de la sintaxis. En Félix San Vicente (dir.). Gramática contrastiva de referencia de español para italófonos. Bolonia: CLUEB, vol. III, pp. 879-909.

2015b. Terminología gramatical española de los principios / Principios de la terminología gramatical española. En Cécile Bruley \& Javier Suso López (eds.). $L a$ terminología gramatical del español y del francés: emergencias, transposiciones, traducciones y contextualizaciones. Frankfurt am Main-Berlin-Bern: Peter Lang, pp. 25-74.

Gómez Asencio, José J. y Martín Gallego, Carolina. 2014. Apuntes para una historia de la gramatización de los ahora llamados "conectores (discursivos, textuales)": del XV al XX. En José M. Bustos Gisbert y José J. Gómez Asencio (coords.). Procedimientos de conexión discursiva en español: adquisición y aprendizaje. Bern-New York-Berlin: Peter Lang, pp. 81-126.

Swiggers, Pierre. 2009. Terminología gramatical y lingüística: elementos de análisis historiográfico y metodológico. Res Diachronicae Virtual 7: 11-35. 
